\title{
The presence of Mycoplasma pneumoniae infection and GM1 ganglioside antibodies in Guillain-Barré syndrome
}

\author{
Mridula B Sharma ${ }^{1}$, Rama Chaudhry ${ }^{1}$, Irum Tabassum ${ }^{1}$, Nishat Hussain Ahmed ${ }^{1}$, Jitendra \\ Kumar Sahu ${ }^{2}$, Benu Dhawan ${ }^{1}$, Veena Kalra ${ }^{2}$ \\ ${ }^{1}$ Department of Microbiology, All India Institute of Medical Sciences, New Delhi, India \\ ${ }^{2}$ Department of Pediatrics, All India Institute of Medical Sciences, New Delhi, India
}

\begin{abstract}
Introduction: Guillain-Barré syndrome (GBS) is an autoimmune disorder affecting the peripheral nervous system, usually triggered by an acute infection. GBS patients are known to have antecedent bacterial infections associated with auto-antibodies to various gangliosides. This investigation aimed to evaluate GBS patients for serological evidence of Mycoplasma pneumoniae infection and anti GM1 ganglioside antibodies.

Methodology: This cross-sectional study included 57 pediatric GBS patients, 42 neurological controls (i.e., non-GBS Acute Flaccid Paralysis cases) and 35 non-neurological controls. Enzyme linked immune sorbent assay (ELISA) was performed on the sera of the subjects to detect IgM and IgG antibodies against Mycoplasma (M.) pneumoniae and GM1 gangliosides.

Results: The results showed that $15.79 \%$ and $21.05 \%$ GBS patients were positive for IgG and IgM antibodies against M. pneumoniae as compared to $2.38 \%(\mathrm{P}<0.05)$ and $14.2 \%$ in non-GBS-AFP and $5.7 \%$ and $14.2 \%$ in non-neurological controls respectively. Additionally, $43.85 \%$ and $38.54 \%$ GBS patients were positive for IgG and IgM antibodies against GM1 gangliosides as compared to $38.09 \%$ and $28.57 \%$ in non-GBS-AFP and $14.2 \%$ and $2.84 \%$ in non-neurological controls respectively $(\mathrm{P}<0.05)$.

Conclusions: Significant difference in levels of IgG antibodies against M. pneumoniae was observed between GBS patients and neurological controls, suggesting M. pneumoniae to be an important antecedent to GBS. Significant difference in levels of anti GM1 ganglioside antibodies (IgG \& IgM) was seen between GBS patients and non-neurological controls, highlighting its possible role in the pathogenesis of GBS.
\end{abstract}

Key words: GM1 Gangliosides; Guillain-Barré syndrome; Mycoplasma pneumoniae; Non-GBS-acute flaccid paralysis

J Infect Dev Ctries 2011; 5(6):459-464.

(Received 18 August 2010 - Accepted 19 February 2011)

Copyright (C) 2011 Sharma et al. This is an open-access article distributed under the Creative Commons Attribution License, which permits unrestricted use, distribution, and reproduction in any medium, provided the original work is properly cited.

\section{Introduction}

Guillain-Barré syndrome (GBS, with the incidence of 1 or 2 people per 100,000 , is one of the leading causes of non-trauma-induced paralysis in the world [1]. In its most common form, it is an acute, demyelinating paralytic disease of the peripheral nervous system. The segmental demyelination of peripheral nerves is thought to be immune mediated and both humoral and cell-mediated immune mechanisms have been implicated. About two thirds of the patients report preceding illnesses (usually respiratory or gastro-intestinal infections) within 12 weeks before the onset of the neurologic illness [2]. In most cases, the precise infection is not clear from the medical history and has often resolved by the time neuropathic symptoms develop.

Many authors believe that the mechanism of disease involves an abnormal $\mathrm{T}$-cell response precipitated by an infection. Some of the pathogenic triggers of GBS include Epstein-Barr virus, cytomegalovirus, the enteroviruses-hepatitis A and B, varicella, Mycoplasma pneumoniae, and Campylobacter jejuni, which is perhaps the most common, being reported in $17 \%$ to $66 \%$ of GBS patients. These pathogens are believed to activate CD4+ helper-inducer T cells, which are particularly important mediators of disease. Prior infection with M. pneumoniae is reported to be found in up to $5 \%$ of GBS patients. GBS after M. pneumoniae infections is reported to be more in younger patients than other GBS patients, but their clinical patterns do not have unique features as in the case of $C$. jejuni infections [3-7].

A flurry of literature suggests the presence of various anti-ganglioside antibodies in the sera of patients with GBS. A possible role of these 
Table 1. ELISA results of GBS patients and controls

\begin{tabular}{|l|l|l|l|l|l|}
\hline Investigation & $\begin{array}{l}\text { GBS patients } \\
(\mathbf{n}=\mathbf{5 7})\end{array}$ & $\begin{array}{l}\text { Neurological } \\
\text { controls } \\
(\mathbf{n}=\mathbf{4 2})\end{array}$ & $*$ P value & $\begin{array}{l}\text { Non neurological } \\
\text { controls } \\
(\mathbf{n}=\mathbf{3 5})\end{array}$ & **P value \\
\hline $\begin{array}{l}\text { IgG ELISA for } \\
\text { pneumoniae }\end{array}$ & $9(15.79 \%)$ & $1(2.38 \%)$ & 0.040 & $2(5.7 \%)$ & 0.474 \\
\hline $\begin{array}{l}\text { IgM ELISA for } \\
\text { pneumoniae }\end{array}$ & $12(21.05 \%)$ & $6(14.2 \%)$ & 0.440 & $5(14.2 \%)$ & 0.582 \\
\hline $\begin{array}{l}\text { IgG ELISA for GM1 } \\
\text { gangliosides }\end{array}$ & $25(43.85 \%)$ & $16(38.09 \%)$ & 0.680 & $5(14.2 \%)$ & 0.005 \\
\hline $\begin{array}{l}\text { IgM ELISA for GM1 } \\
\text { gangliosides }\end{array}$ & $22(38.54 \%)$ & $12(28.57 \%)$ & 0.392 & $1(2.84 \%)$ & $<0.001$ \\
\hline
\end{tabular}

${ }^{*} \mathrm{P}$ value for comparison of variables between GBS patients and neurological controls

**P value for comparison of variables between GBS patients and non-neurological controls

autoantibodies has been postulated in the pathogenesis of the syndrome. GM1 ganglioside is the most abundant of the four major gangliosides present in the brain tissues, although more than 100 different gangliosides have been identified so far on the basis of difference in number and position of sialic acid residues. The frequency of anti-GM1 antibodies in GBS patients varies from $2 \%$ or less to $30 \%$ in various studies [8-17].

In the present study, we evaluated serum $\operatorname{IgG}$ and IgM antibodies against GM1 gangliosides and Mycoplasma pneumoniae by enzyme linked immune sorbent assay (ELISA) in pediatric patients of GBS and in neurological and non-neurological controls. This is the first study in a pediatric age group from India, which aims to investigate the role of $M$. pneumoniae as a precedent and anti-GM1 ganglioside antibodies in the pathogenesis of GBS.

\section{Methodology}

The study was conducted from September 2003 to October 2006 in a tertiary care medical centre in Delhi, North India. Approval of the Institutional Ethics Committee was received prior to beginning the study and written informed consent was obtained from the parent or legal guardian of each participant.

The study cohort consisted of 57 cases, which included children who met the diagnosis of GuillainBarré syndrome according to the criteria of Asbury and Cornblath [18]. Two groups of controls were studied. The neurological control group consisted of 43 patients with neurological diseases (acute flaccid paralysis other than Guillain-Barré syndrome), who were admitted serially after the Guillain-Barré syndrome cases. Diagnoses of these patients included transverse myelitis, traumatic neuritis, postdiphtheric polyneuropathy, cranio-vertebral junction anomaly, and unexplained neuropathy. The second hospital control group consisted of patients admitted during the same time as the patients with GuillainBarré syndrome, who had presenting symptoms of other diseases, and were not presenting and/or having past history of any neurological illness.

A detailed history of neurological illness, preceding respiratory illness within 12 weeks before the onset of the neurologic illness, fever, and intramuscular injections was obtained. Clinical details regarding the onset, progression, and involvement of respiratory muscles and autonomic symptoms were recorded. Involvement of respiratory muscles was assessed by careful serial evaluations as well as by monitoring of vitals and blood gases. Autonomic dysfunction was established if patients had urinary incontinence or retention, blood pressure lability, hypertension, or electrocardiogram evidence of loss of variation in the time elapsing between two consecutive $\mathrm{R}$ waves in the electrocardiogram ( $\mathrm{RR}$ interval variation) with respiration or persistent arrhythmia. The patients were considered to have bulbar palsy if they had dysarthria and/or dysphagia during the course of the illness. Bulbar palsy was confirmed on examination when poor elevations of the soft palate uvula, diminished soft palate reflex, and/or inability to swallow secretions safely were observed.

At admission, pretreatment serum samples on day one were obtained from patients and controls. The serum samples were kept frozen at $-70^{\circ} \mathrm{C}$ until serologic assays were done.

ELISA for antibodies against M. pneumoniae

The presence of serum IgG and IgM antibodies specific for $M$. pneumoniae was determined by ELISA using a commercial kit (Virion-Serion, 
Table 2. Clinico-epidemiological profile of Guillain-Barré syndrome patients with recent $M$. pneumoniae infection

\begin{tabular}{|l|c|c|c|}
\hline Characteristics & $\begin{array}{l}\text { Positive for M. } \\
\text { pneumoniae group } \\
(\mathbf{n = 1 2 )}\end{array}$ & $\begin{array}{l}\text { Negative for M. } \\
\text { pneumoniae group } \\
(\mathbf{n = 4 5 )}\end{array}$ & P-value \\
\hline Mean age in years ( \pm SD) & $5.3( \pm 2.9)$ & $5.9( \pm 3.6)$ & 0.591 \\
\hline Male respiratory & $11(91.6 \%)$ & $30(66.7 \%)$ & 0.083 \\
\hline $\begin{array}{l}\text { Preceding upper } \\
\text { infection }\end{array}$ & $3(25 \%)$ & $8(17.8 \%)$ & 0.421 \\
\hline Quadriparesis & $8(66.7 \%)$ & $30(71.4 \%)$ & 0.642 \\
\hline Bulbar weakness & $4(33.3 \%)$ & $12(26.7 \%)$ & 0.450 \\
\hline
\end{tabular}

Wurzburg, Germany) following the manufacturer's instructions. The specimen was considered positive for antecedent $M$. pneumoniae infection if an elevated IgM and/or IgG titer of $>20 \mathrm{U} / \mathrm{ml}$ against M. pneumoniae antigens was seen.

\section{ELISA for antibodies against GM1 gangliosides}

The presence of serum IgG and IgM antibodies specific for GM1 gangliosides were determined by ELISA using a commercial kit (Buhlmann Laboratories, Schönenbuch, Switzerland) following manufacturer's instructions. Positive values were defined as elevated IgG and/or IgM antibodies $>800$ $\mathrm{U} / \mathrm{ml}$ against GM1 ganglioside antigens.

\section{Statistical analysis}

The SPSS version 10 (SPPS, Inc, Chicago, Illinois) was used for data analysis. Frequencies and means were calculated by descriptive analysis. All the reported $\mathrm{P}$ values were two-sided, and a $\mathrm{P}$ value $<0.05$ was considered significant. The Chi-squared test or Fisher's exact test was used for comparing categorical variables (Tables $1 \& 2$ ). Chi-squared test was performed for variables with a frequency of five or more (e.g., for IgM ELISA for M. pneumoniae, IgG ELISA for GM1 gangliosides, and IgM ELISA for GM1 gangliosides between GBS and neurological controls; for IgM ELISA for M. pneumoniae and IgG ELISA for GM1 gangliosides between GBS and nonneurological controls; and for male sex between $M$. pneumoniae positive and negative groups, etc.). Fisher's exact test was performed for variables with a frequency of less than five (e.g., for IgG ELISA for $M$. pneumoniae between GBS and neurological controls; for IgG ELISA for M. pneumoniae and IgM ELISA for GM1 gangliosides between GBS and non-neurological controls; and for bulbar weakness between $M$. pneumoniae positive and negative groups, etc.). The Mann-Whitney test was used for comparing continuous variable, e.g., age in Table 2.

\section{Results}

A total of 54 patients with a clinical diagnosis of Guillain-Barré syndrome, 43 neurological controls, and 42 hospital controls were studied. The mean age of the patients was 5.8 years $(\mathrm{SD} \pm 3.4)$; of the neurological controls $6.2(\mathrm{SD} \pm 3.2)$ years; and of the hospital controls $5.4(\mathrm{SD} \pm 3.2)$ years. There was no significant difference in age among the three groups.

ELISA for antibodies against $\mathrm{M}$. pneumoniae

GBS Patients: Out of 57 GBS patients, nine $(15.79 \%)$ and $12(21.05 \%)$ were found to be positive for $\mathrm{IgG}$ and $\mathrm{IgM}$ antibodies against Mycoplasma pneumoniae respectively.

Neurological Controls: Out of 42 neurological controls, one $(2.38 \%)$ and six $(14.20 \%)$ were found to be positive for $\operatorname{IgG}$ and $\operatorname{IgM}$ antibodies against $M$. pneumoniae respectively.

Non-neurological Controls: Out of 35 nonneurological controls, two (5.7\%) and five (14.20\%) were found to be positive for IgG and IgM antibodies against Mycoplasma pneumoniae respectively.

\section{ELISA for antibodies against GM1 gangliosides}

GBS Patients: Out of 57 GBS patients, 25 (43.85\%) and $22(38.54 \%)$ patients were positive for IgG and IgM antibodies against GM1 ganglioside respectively.

Neurological Controls: Out of 42 neurological controls, $16(38.09 \%)$ and $12(28.57 \%)$ patients were positive for IgG and IgM antibodies against GM1 ganglioside respectively.

Non-neurological Controls: Out of 35 nonneurological controls, five (14.20\%) and one (2.84\%) patients were positive for IgG and IgM antibodies against GM1 ganglioside respectively.

Statistical analysis: Statistically significant difference in levels of IgG antibodies against $M$. pneumoniae was observed between GBS patients and neurological controls $(\mathrm{P}=0.040)$. 
A statistically significant difference was observed in levels of anti GM1 ganglioside IgG antibodies between GBS patients and nonneurological controls $(\mathrm{P}=0.005)$ and also in levels of anti GM1 ganglioside IgM antibodies between GBS patients and non-neurological controls $(\mathrm{P}<0.001)$.

No significant difference was observed among other parameters between GBS patients and controls.

Clinical profile of GBS patients with recent $\mathrm{M}$. pneumoniae infections

The clinico-epidemiological profile of GBS patients with recent $M$. pneumoniae infection is depicted in Table 2. There was no significant difference in age between the $M$. pneumoniae infection positive $(5.3 \pm 2.9$ years) and the $M$. pneumoniae infection negative $(5.9 \pm 3.6$ years $)$ groups. No statistical difference was observed between the $M$. pneumoniae positive and the $M$. pneumoniae negative groups with respect to age, sex, preceding upper respiratory infection, quadriparesis, bulbar weakness and other clinical features.

\section{Discussion}

The pathogenesis of Guillain-Barré syndrome, which is one of the leading causes of non traumainduced paralysis, remains ill defined [19]. In our study, the presence of antibodies (both IgG and IgM) against M. pneumoniae and GM1 Ganglioside was investigated in 57 GBS patients, 42 neurological controls, and 35 non-neurological controls. The male preponderance of GBS patients was observed in the study as generally recognized $[9,19]$.

We have earlier reported a clinical association of childhood transverse myelitis patients with GM1 antibodies. We have also earlier reported a corelation of GBS with $C$. jejuni in the same study population; antecedent $C$.jejuni infection was found in $27.7 \%$ of GBS patients as compared with $2.3 \%$ in neurological controls and $2.3 \%$ in non-neurological controls [20,21]

In the present study, we found that 12 out of 57 GBS patients $(21.05 \%)$ had recent $M$. pneumoniae infection (IgM antibodies positive) as compared to $14.2 \%$ each in the neurological and non-neurological controls. This difference was not statistically significant. Among these $12 \mathrm{M}$. pneumoniae IgM antibodies positive GBS patients, nine (15.79\%) were also positive for IgG antibodies against $M$. pneumoniae as compared to one $(2.38 \%)$ and two $(5.7 \%)$ in the neurological and non-neurological controls respectively. A statistically significant difference was observed in this criterion among GBS patients and neurological controls. In published literature, M. pneumoniae infection is seen in $1-25 \%$ of GBS patients. Jacobs et al. and Hughes et al. have reported $M$. pneumoniae sero-positivity in $5 \%$ and $2 \%$ of GBS patients as compared to $1 \%$ and $0.5 \%$ in controls respectively [4,18]. From the Indian subcontinent, one study in adult GBS patients has shown $50 \%$ of patients to be positive for antibodies against M. pneumoniae, as compared to $25 \%$ of household controls and $15 \%$ of hospital controls when tested by the gelatin particle agglutination (GPA) test [5]. Other previous studies in adult GBS patients have also reflected a high frequency of antecedent $M$. pneumoniae infection in GBS patients from India [22-24]. Some of the other studies suggest that recent M. pneumoniae infection was identified occasionally in GBS patients, but not significantly more often than in controls [25]. The wide range of variation in $M$. pneumoniae infection association with GBS (1-25\%) may be attributed to differences in the study populations, the number of included patients, and the methods used for detection of antibodies against $M$. pneumoniae.

In the present study, we also tested antibodies against GM1 gangliosides. A significant difference was seen between GBS patients and non-neurological controls for both IgG and IgM classes of antibodies against GM1 gangliosides. No significant difference was found among GBS patients and neurological controls. There are very few reports regarding the presence of anti-GM1 antibodies following $M$. pneumoniae infections in GBS patients. In a study by Hao et al., one out of two GBS patients with $M$. pneumoniae infection showed elevated levels of antiGM1 antibodies. However, the increased concentration of the antibodies did not reach the statistical significance in comparison with that of the controls [15]. There have been reports suggesting that sera from patients with peripheral neuropathies, including GBS subsequent to $M$. pneumoniae infections, had auto-antibodies to various glycolipids such as sialosyl lactosaminyl paragloboside, GM1, GD1b and asialo-GM1, etc. [17,24-27].

M. pneumoniae, as a pathogenic micro-organism, elicits both innate and acquired immunities. The cell membrane of $M$. pneumoniae contains lipoproteins that are potent inducers of cytokines equivalent to bacterial lipopolysaccharides and its cytoplasm contains potent immunogenic substances, such as glycolipids and glycoproteins. This pathogen has the ability to stimulate antibodies against carbohydrate 
antigens that are shared by human cells; thus autoimmunity is elicited through their molecular mimicry of various human cell components, specifically of brain tissue. It has been reported that M. pneumoniae carries both the ganglioside GM1 and galactocerebroside epitopes. The immunologic pathomechanism has been suggested to involve antigalactocerebroside antibodies and anti-ganglioside antibodies, while antibodies to GM1 are considered to be more pathogenic than that to galactocerebroside [17,24-29].

For the management of GBS patients, plasma exchange therapy and/or intravenous infusion with a human immunoglobulin preparation are used. Despite the frequent use of these treatments, many patients still have diminished power and sensation one year after onset, often with disturbing effects. More effective management and prevention strategies based on full knowledge of the syndrome's molecular pathogenesis are therefore required. Timely diagnosis and correct treatment of important antecedent infections can be one of such interventions, which can reduce the occurrence of post infectious GBS [29].

\section{Conclusion}

The findings of this study have provided evidence toward the existing hypothesis of $M$. pneumoniae infections as an antecedent to GBS and its possible role in the determination of the specificity of the resulting cross-reactive anti-glycolipid antibodies presumably due to molecular mimicry. However, further studies are needed to clarify this association as well as to look for antibodies against other glycolipids such as sialosyl lactosaminyl paragloboside, galactocerebroside, GDla, GD1b, GD3 and asialo-GM1, etc., for full understanding of the patho-genesis of this very important neurological disease.

\section{References}

1. Guillain-Barré (GBS) definition. www.mayoclinic.com/health/guillain barre syndrome/ DS00413. Accessed 8-20-2009.

2. Arnason B and Soliven B (1993) Acute Inflammatory Demyelinating Polyraducouloneuropathy. In: Dyck P J, Thomas P K, Griffin J W, Low P A, Poduslo J F, editors. Peripheral Neuropathy. $3^{\text {rd }}$ edn. Saunders, Philadelphia.1437-1497.

3. Dowling PC, Cook SD (1981) Role of Infection in GuillainBarré Syndrome: Laboratory Confirmation of Herpes viruses in 41 Cases. Ann Neurol 9 Suppl: 44-45.

4. Jacobs BC, Rothbarth PH, Van der Meche FGA, Herbrink P, Schmitz PIM, De Klerk MA, Van Doom PA (1998) The Spectrum of Antecedent Infections in Guillain-Barré
Syndrome: A Case-Control Study. Neurology 51: 11101115.

5. Gorthy SP, Kapoor L, Chaudhry R, Sharma N, Panigrahi P, Behari M (2006) Guillain-Barré Syndrome : Association with Campylobacter jejuni and Mycoplasma pneumoniae Infections in India. Natl Med J India. 19: 137-139.

6. Ogawara K, Kuwabara S, Mori M, Hattori T, Koga M, Yuki N (2000) Axonal Guillain- Barré syndrome: relation to antiganglioside antibodies and Campylobacter jejuni infection in Japan. Ann Neurol 48: 624-631.

7. Sinha S, Prasad KN, Jain D, Pandey CM, Jha S, Pradhan S (2007) Preceding infections and anti-ganglioside antibodies in patients with Guillain-Barré syndrome: a single centre prospective case-control study. Clin Microbiol Infect 13: 334-337.

8. Kusunoki S, Chiba A, Hitoshi S, Takizawa H, Kanazawa I (1995) Anti-Gal-C Antibodies in Auto-immune Neuropathies Subsequent to Mycoplasma Infection. Muscle Nerve 18: 409-413.

9. Tseng BS, Sheikh S, Markowitz JA (2009) Guillain-Barré Syndrome in Childhood. eMedicine Specialties > Neurology $>$ Pediatric Neurology. Accessed 06-24-2010.

10. Schessl J, Koga M, Funakoshi K, Kirschner J, Muellges W, Weishaupt A, Gold R, Korinthenberg R (2007) Prospective study on anti-ganglioside antibodies in childhood GuillainBarré syndrome. Arch Dis Child 92: 48-52.

11. Enders U, Karch H, Toyka KV, Michels M, Zielasek J, Pette M, Heesemann J, Hartung HP (1993) The Spectrum of immune Responses to Campylobacter jejuni and Glycoconjugates in Guillain-Barré Syndrome and in other Neuro-immunological Disorders. Ann Neurol.34: 136-144.

12. Simone LL, Annuziata P, Maimone D, Liguori M, Leante R, Livrea P (1993) Serum and CSF anti-GM1 Antibodies in Patients with Guillain-Barré Syndrome and Chronic Inflammatory Demyelinating Polyneuropathy. J Neurol Sci 114: 49-55.

13. Van den Berg LH, Marrink J, de Jager AEJ, de Jong HJ, van Imhoff GW, Latov N, Sadiq SA (1993) Anti-GM1 Antibodies in Patients with Guillain-Barré Syndrome. J Neurol Neurosurg Psychiatry 55: 8-11.

14. Vriesendorp FJ, Mishu B, Blaser MJ, Koski CL (1993) Serum Antibodies to GM1, Gd1b, Peripheral Nerve Myelin, and Campylobacter jejuni in Patients with Guillain-Barré Syndrome and Controls: Correlation and Prognosis. Ann. Neurol. 34: 130-135.

15. Hao Qi, Saida T, Kuroki S, Nishimura M, Nukina $M$, Obayashi H, Saida K (1998) Antibodies to Gangliosides and Galactocerebroside in Patients with Guillain-Barré Syndrome with Preceding Campylobacter jejuni and other Identified Infections. J Neuroimmunol 81: 116-126.

16. Willison HJ and Yuki N (2002) Peripheral Neuropathies and Anti-Glycolipid Antibodies. Brain 125: 2591-2626.

17. Ang CW, Tio-Gillen AP, Groen J, Herbrink P, Jacobs BC, Van Koningsveld R, Osterhaus ADME, Van der Meche FGA, van Doorn PA (2002) Cross-reactive Antigalactocerebroside Antibodies and Mycoplasma pneumoniae Infections in Guillain-Barré Syndrome. J Neuroimmunol 130: $179-183$.

18. Asbury AK and Cornblath DR, (1990) Assessment of Current Diagnostic Criteria for Guillain-Barré Syndrome. Ann Neurol 27: S21-S24. 
19. Hughes RAC, Hadden RDM, Gregson NA, Smith KJ (1999) Pathogenesis of Guillain-Barré Syndrome. J Neuroimmunol 100: 74-97.

20. Kalra V, Sharma S, Sahu J , Sankhyam N, Chaudhry R, Dhawan B, Mridula B (2009) Childhood acute transverse myelitis-clinical profile, outcome and association with antiganglioside antibodies . J Child Neurol.24: 466-471.

21. Kalra V, Chaudhry R, Dua T, Dhawan B, Sahu JK, Mridula B (2009) Association of Campylobacter jejuni Infection with Childhood Guillain-Barré syndrome: A Case-Control Study. J Child Neurol 24: 664-668.

22. Dey A B, Chaudhry R, Kumar P, Nisar N, Nagarkar KM (2000) Mycoplasma pneumoniae and Community Acquired Pneumonia. Natl Med J Ind 13: 66-70.

23. Pandey A, Chaudhry R, Nisar N, Kabra S K (2000) Acute Respiratory Tract infections in Indian Children with Special Reference to Mycoplasma pneumoniae. J Trop Paeds 46: 371-374.

24. Ponka A (1980) Central Nervous System Manifestations Associated with Serologically Verified Mycoplasma pneumoniae Infection. Scand J Infect Dis 12: 175-184.

25. Yoshino H, Inuzuka T, Miyatake T (1992) IgG Antibody against GM1, GD1b and Asialo-GM1 In Chronic Polyneuropathy Following Mycoplasma pneumoniae Infection. Eur Neurol 32: 28-31.
26. Kusunoki S, Chiba A, Hitoshi S, Takizawa H, Kanazawa I (1995) Anti-Gal-C Antibodies in Auto-immunne Neuropathies Subsequent to Mycoplasma Infection. Muscle Nerve 18: 409-413.

27. Katsuhiko K, Tagawa Y, Honda A, Yuki N (1998) GuillainBarré Syndrome with Anti-GM1b Antibody Subsequent to Mycoplasma pneumoniae Infection. J Neurol Scin. 156: 99101.

28. Narita M (2009) Pathogenesis of neurological manifestations of Mycoplasma infections. Pediatr neurol. 41 (3): $159-168$

29. Susuki K, Odaka M, Mori M, Hirata K, Yuki N (2004). Acute motor axonal neuropathy after Mycoplasma infection: evidence of molecular mimicry.Neurology 62: 949-56.

\section{Corresponding author}

Rama Chaudhry

Professor

Department of Microbiology

All India Institute of Medical Sciences

New Delhi, India

Email: drramach@gmail.com

Conflict of interests: No conflict of interests is declared. 